\title{
EL CLUB DEPORTIVO COMO MARCO DE SOCIABILIDAD EN ESPAÑA. UNA VISIÓN HISTÓRICA (1850-1975)
}

\author{
por
}

\section{Xavier Pujadas}

Universitat Ramon Llull, Barcelona

\section{CARLES SANTACANA}

Universitat de Barcelona

RESUMEN: En una perspectiva de bistoria social y cultural del deporte, el análisis de los procesos de instauración y desarrollo asociativos es fundamental para esclarecer la articulación social de la actividad deportiva moderna. Junto al rol articulador $y$ racionalizador de la práctica física, el estudio histórico del asociacionismo deportivo debe mostrarnos los tipos de relación social que se establecen, y la evolución de estos en función de los protagonistas, el marco sociobistórico en el que se integran y el discurso ideológico en el que se sitúan.

Palabras Clave: Club deportivo, Deporte, España. Fútbol, Siglos XIX y XX. Sociabilidad.

ABSTRACT: In the social and cultural history of sport, the analysis of the establishment and development of associations is fundamental in clarifying the social articulation of modern sporting activity. Along with its role in regard to promoting physical exercise, the historical study of sporting associations can also reveal the kinds of social relation which are established and the evolution of these relations, and the ideological and socio-bistorical contexts in which they are embedded.

KEY WORDS: Sporting clubs. Sport. Spain. Football. Nineteenth century. Twentieth century. Sociability.

En una perspectiva de historia social y cultural del deporte, el análisis de los procesos de instauración y desarrollo asociativos es fundamental para esclarecer la articulación social de la actividad deportiva moderna. En primer lugar porque la institucionalización asociativa jugó un papel crucial en la aparición 
del deporte moderno en el marco de la Inglaterra victoriana ${ }^{1}$, y por consiguiente en el resto de los países occidentales donde se fue desarrollando la práctica deportiva a partir del modelo original británico, ya a partir de la segunda mitad del siglo XIX.

En estas páginas, tras algunos apuntes referentes a la sociabilidad deportiva en general, pretendemos seguir la evolución de la sociabilidad deportiva a través de sus rasgos más generales en España desde la incorporación de las primeras manifestaciones del deporte moderno y la creación de clubs en las zonas del país que reciben la influencia británica o continental en los años setenta del siglo XIX, hasta el final del franquismo.

\section{LA «SOCIABILIDAD DEPORTIVA» EN PERSPECTIVA HISTÓRICA}

Como es ya de sobras conocido, el paso del juego y de la actividad física premodernas a las nuevas formas deportivas conllevó la normativización y la organización asociativa de las prácticas, en la misma medida en que el complejo marco social y político que caracterizaba el Estado liberal naciente se iba institucionalizando y burocratizando. La necesaria compartimentación de la vida en la sociedad industrial vinculada a una nueva idea de productividad - tiempo de ocio, tiempo de trabajo...- así como la racionalización de las formas de organización política, no fueron en absoluto ajenas a la aparición de las modernas formas de ocio, en buena medida espejo y a la vez laboratorio de las formas de relación social que aparecieron con la sociedad burguesa ${ }^{2}$.

Junto a este rol articulador y racionalizador de la práctica física, el estudio histórico del asociacionismo deportivo debe mostrarnos los tipos de relación social que se establecen, y la evolución de estos en función de los protagonistas, el marco sociohistórico en el que se integran y el discurso ideológico en el que se sitúan. El análisis de estos factores es revelador para la comprensión de las dinámicas sociales y culturales dominantes, sus fracturas y contradicciones en el ámbito de la vida cotidiana y el ocio contemporáneos ${ }^{3}$.

Desde este punto de vista, el estudio histórico de la sociabilidad en el contexto de las organizaciones deportivas debe ser mucho más que el análisis de las

1 Holt, Richard: Sport and the British. A modern history, Oxford, Clarendon Press, 1992. El capítulo $2^{\circ}$ es especialmente interesante para el análisis de este proceso.

2 DuRING, Bertrand: Des jeux aux sports. Repères et documents en bistoire des activités physiques, $\mathrm{Pa}-$ ris, Vigot, 1984, p. 103.

3 Ver URÍA, Jorge: «El nacimiento del ocio contemporáneo. Algunas reflexiones sobre el caso español», en VACA LORENZO, Ángel: Fiesta, juego y ocio en la bistoria. XIV Jornadas de Estudios Históricos organizadas por el Departamento de Historia Medieval, Moderna y Contemporánea, Salamanca, Ediciones Universidad de Salamanca (Acta salmanticensia, 121), 2003, pp. 347-382.

Hispania, LXIII/2, núm. 214 (2003) 505-522 
relaciones entre semejantes que forman parte de asociaciones de deportistas ${ }^{4}$. Fundamentalmente, nos referiremos aquí a organizaciones de practicantes, a pesar de que evidentemente la institucionalización deportiva conlleva muchas otras formas organizacionales (de directivos, federativas, arbitrales, jurídicas, etc.).

En la línea de la definición propuesta por Pierre Arnaud ya hace algunos años sobre el concepto de "sociabilidad deportiva» en perspectiva histórica, aquello que nos interesa investigar es pues el resultado de «un conjunto de determinaciones múltiples, dirigidas a establecer lazos o redes de afinidad y cuyas bases son territoriales, de género, socio-profesionales (corporativas), ideológicas, generacionales...»s.

Evidentemente, en este sentido aparece como ineludible el club deportivo como objeto de estudio del modelo clásico de forma de organización de practicantes y espectadores deportivos, y que constituye uno de los «rasgos distintivos de los pasatiempos de talante deportivo» ${ }^{6}$. Este tipo de institución, de origen británico - - entendida ya en el siglo XVIII como «asociación libre de hombres libres", bien sea con fines políticos, culturales o de ocio-, adquiere en el ámbito deportivo un especial significado para su desarrollo y expansión territorial. Básicamente porque el club deportivo estructurado actuará como agente intermediario entre la reglamentación y el practicante. Es decir, será la pieza fundamental para uniformar las normativas de los juegos - a menudo con pautas muy distintas según la región, ciudad o escuela donde los jóvenes las ejecutaban espontáneamente- y el espacio de sociabilidad adecuado para su institucionalización y reproducción.

El club deportivo, por lo tanto, se convierte hasta la articulación de una estructura jurídico-deportiva más compleja a finales del siglo XIX - federativa, de adscripción nacional e internacional y paulatinamente profesionalizada - en la plataforma de control, arbitraje, práctica, reglamentación y jerarquización del deporte moderno, que se desarrolla bajo unas formas de sociabilidad específicas. Generalmente, estas formas de sociabilidad están vinculadas inicialmente a expresiones sociales elitistas, de una gran impermeabilidad y discriminatorias.

Desde la segunda mitad del siglo XVIII, la creación de los primeros clubes en el sur de Inglaterra responde en efecto a la necesidad de reunión de sectores de la gentry con el fin de uniformizar las reglas para desarrollar prácticas físicas con apuestas o bien para simplemente organizarlas. Las primeras reglamentaciones modernas de juegos deportivos, muy ligadas a las apuestas de la gentry inglesa se desarrollarán esporádicamente desde mediados del siglo XVIII, co-

\footnotetext{
4 Una síntesis introductoria al fenómeno organizacional en GARCÍA FERRANDO, Manuel: «La organización social del deporte», en GARCíA FERRANDO, Manuel et al., Sociología del deporte, Madrid, Alianza, 1998.

5 Desde este punto de vista metodológico, Pierre Arnaud estudió las sociedades de deporte en la Francia anterior a la I ${ }^{a}$ Guerra Mundial (ARNAUD, Pierre: «Les sociétés sportives avant 1914», Les cabiers de lanimation, Lyon, $\mathrm{n}^{\circ}$ 54, 1986, p. 73).

6 Elias, N. y DunNing, E.: Sport et civilisation. La violence maîtrisée, Paris, Fayard, 1994, p. 49.
} 
mo en el caso del cricket, la equitación o la lucha cuerpo a cuerpo. La mayoría de los deportes atléticos nacerán con la normativización escolar del siglo XIX ${ }^{7}$.

En general, sus miembros formaban parte de la aristocracia (grandes propietarios), de la Iglesia, del ejército y de la clase política. El nacimiento de clubs atléticos - relacionados con el foot-ball, el rugby, el pedestrismo o el remoes posterior, a mediados del Ochocientos, y refleja en parte el ascenso de la burguesía industrial y de los profesionales liberales urbanos. Sin embargo, el modelo de club inglés, estructurado alrededor de una reglamentación estatutaria que dificulta su apertura social, y que recrea las costumbres sociales de las nuevas clases dominantes liberales, se mantiene en sus líneas generales.

Durante la segunda mitad del siglo XIX, el fenómeno deportivo se extiende progresivamente a través de las áreas industriales, urbanas y/o portuarias del continente europeo y se consolida en las ciudades de la costa Este de Estados Unidos. La herencia colonial británica había impulsado en efecto el desarrollo de sociedades deportivas en ese país desde finales del siglo XVIII. No es de extrañar, por lo tanto, que el proceso industrializador posterior posibilite una consolidación más rápida del deporte que en Europa ${ }^{8}$.

En Europa Occidental, la expansión deportiva se encuentra en el período inicial muy ligada al modelo inglés de club deportivo, a sus referentes formales, estéticos y estructurales. Sin embargo, la especificidad social, política y cultural de cada región hace posible modelos de sociabilidad y de desarrollo del ocio deportivo con características distintivas9. Sin embargo, el estudio histórico de los modelos de sociabilidad deportiva, bien desarrollado sobre todo para el caso francés ${ }^{10}$, ha sido escasamente abordado por la historiografía española más allá de visiones fragmentarias sobre algunos clubs. Si bien la celebración de centenarios de determinadas instituciones ha generado alguna aportación notable ${ }^{11}$, las sombras son todavía mucho más abundantes que la luz al respecto.

7 Holt, R.: Sport and the British, op. cit. Ver también las comunicaciones presentadas al $14^{\circ}$ congreso internacional de la I.S.C.H.E. [International Standing Conference for the History of Education]: Educació, Activitats Físiques i Esport en una perspectiva bistórica XIV ISCHE Conference 1992, Barcelona, Imprenta Barcelonesa, 1992, 2 vols.

8 Este proceso se puede seguir en RIESS, S. A.: Sport in industrial America, 1850-1920, Wheeling, H.D., 1995.

9 Algunas de estas diferencias ya las apuntábamos para la Europa mediterránea en PUJADAS, Xavier y SANTACANA, Carles: «Deporte y modernización en el ámbito mediterráneo. Reflexiones para una historia comparada (1870-1945)", Cercles. Revista d'bistòria cultural, Barcelona, n 3 , Enero de 2000, pp. 43-58.

10 Por ejemplo a partir de los estudios de Arnaud y Camy iniciados en los años 80: ARNAUD, P. y CAMY, J.: La naissance du mouvement sportif associatif en France, Lyon, P.U.F., 1986.

11 Un ejemplo reciente sería el de BAHAMONDE, Ángel: El Real Madrid en la bistoria de España, Madrid, Taurus, 2002.

Hispania, LXIII/2, núm. 214 (2003) 505-522 


\section{LAS PRIMERAS FORMAS DEL CLUB DEPORTIVO EN ESPAÑA: ¿MODERNIZACIÓN O DISTINTIVO SOCIAL?}

Al igual que sucede en países como Francia o Italia, la incorporación de las prácticas del deporte moderno en España se inició durante la segunda mitad del siglo XIX básicamente a través de las zonas urbanas, portuarias, industriales o con presencia de explotaciones de recursos energéticos que estaban gestionadas por profesionales de origen británico o europeo. Esta penetración deportiva debe vincularse con las relaciones comerciales, diplomáticas y profesionales que se establecieron en el asimétrico proceso industrializador del Ochocientos y a la capacidad de irradiación de las nuevas formas de ocio de los centros urbanos del país.

De hecho, existen lazos estrechos entre la aparición de los primeros clubes deportivos, el origen de sus promotores y el ámbito territorial en el que se registraron, generalmente urbano. Esta relación se puede ver fácilmente en el caso de los primeros clubes futbolísticos registrados en las ciudades españolas a finales del siglo XIX y vinculados a población inglesa o de otras nacionalidades del continente europeo: el Athletic Club de Bilbao (1899), el Huelva Recreation Club (1889), el F. C. Barcelona (1899) o la propia Institución Libre de Enseñanza en Madrid ${ }^{12}$.

En síntesis, podemos afirmar que como sucedió en casi toda Europa Occidental, en España el papel de las ciudades fue central en la implantación de los primeros clubes de deportes ingleses e incluso en la adaptación a formas deportivas modernas de prácticas populares de arraigo rural como la pelota. El papel ejercido per técnicos y profesionales extranjeros en la aparición de sociedades deportivas fue sin duda decisivo para las nuevas entidades deportivas. Pero, como en el caso, por ejemplo, de Barcelona, llegó a provocar la aparición de clubs como la Real Sociedad Española de Foot-ball (1901) -después R.C.D. Español- en oposición al dominio alemán e inglés de la mayoría de sociedades deportivas de la ciudad.

Sin duda; otros factores han de tenerse en cuenta como la demanda incipiente de ocio urbano moderno, ya visible a partir de 1860 en ciudades como Barcelona, Madrid, Bilbao o Sevilla, y muy centrado inicialmente en prácticas como el billar, la acrobacia, la gimnasia, la esgrima o el arte ecuestre. También, la comercialización rápida de actividades físicas como el patinaje sobre hielo en ciudades del interior, el baño de mar y oleaje en la costa, o la necesidad de una infraestructura comunicativa para la captación de asociados que sólo podía encontrarse en el escenario urbano, acaban de explicar la aparición de sociedades deportivas a partir de la década de 1860 en las principales ciudades de España ${ }^{13}$.

12 Este proceso en Pujadas, Xavier y Santacana, Carles: «La mercantilización del ocio deportivo en España. El caso del fútbol. 1900-1928», Historia Social, Valencia, n 47, 2001, pp. 147-167.

13 Para el caso asturiano, ver URía, Jorge: Historia social del ocio Asturias 1894-1914, Madrid, Unión General de Trabajadores, 1996, pp. 205-213. 
En cualquier caso, ¿cómo eran y cómo se organizaban los primeros clubs deportivos españoles? La estructura organizativa y social de los primeros clubs deportivos aparecidos en el último tercio del siglo XIX y hasta los años anteriores a la Primera Guerra Mundial responde a unos rasgos generales comunes a la mayoría de estas instituciones.

En primer lugar, los clubs que inicialmente fomentaban las prácticas de origen inglés eran instituciones que se organizaban siguiendo las pautas estructurales de las entidades originarias de Inglaterra o de los clubs europeos. En este sentido, la aparición más o menos explícita de aspectos de sociabilidad ligados a valores como la igualdad entre practicantes, el prestigio social o público de los miembros de las juntas directivas, o el horizonte de la competitividad y rendimiento como característica de los asociados, se repite incesantemente. Estos aspectos, que pueden completarse con muchos otros elementos vinculados a actividades y formas externas - simbología, uniformidad, terminología usada...- perfilan un origen común de talante liberal burgués, que en ocasiones apunta hacia el elitismo aristocrático y en otras hacia el aburguesamiento de corte emprendedor.

Cabe distinguir pues entre sociedades de carácter netamente aristocrático (como, por ejemplo, la Unión Velocipédica Española (1896) de Madrid con el Marqués de Casa Alta como presidente, el "Lawn-Tennis Club Barcelona»o «Club Inglés» (1899), situado en San Gervasio, alejado del centro populoso y que celebró su fusión con el «Catalunya Lawn Tennis Club» de 1912 en la sede del Fomento del Trabajo Nacional -la organización patronal- o el Real Club Náutico de Barcelona (1909), impulsado por una junta compuesta por el Conde de Fígols, el Vizconde de Güell y el Conde de Belloch entre otros. Otro carácter de tinte burgués menos elitista se puede observar en los inicios del Club Natació Barcelona (1907), situado en la playa de San Sebastián y cuyos estatutos planteaban la existencia de tres categorías de socios - de honor, protectores y activosde los cuales los activos pagaban una cuota mínima de tres pesetas, tenían el derecho a bañarse y tenían voz y voto en las juntas. Tenían pues la marcha del club en sus manos a pesar de no poseer un estatus socioeconómico superior.

Del mismo modo, estos clubs iniciales son instituciones privadas y se organizan en función de la privacidad como un valor importante a tener en cuenta. Lógicamente, eran plataformas de sociabilidad deportiva, y por consiguiente poseían una función y una vertiente colectivizadora, pero en gran medida en función del grupo privado y del individuo privado. En el caso español, y de hecho se puede extender en general al ámbito mediterráneo, los primeros clubs tenísticos, ciclistas o marítimos se articulan alrededor de individuos por afinidades de grupo, en función de su origen social, geográfico, económico e inçuso profesional, o bien por todos ellos en su conjunto ${ }^{14}$.

\footnotetext{
14 Acerca de los clubs ciclistas, ver ROBIN, Claire-Nicolle: «La nouvelle sociabilité sportive en 1900. Les clubs cyclistes", en CARRASCO, Raphä̈l (Ed.): Solidarités et sociabilités en Espagne (XVIXXe siècles), Besançon, Annales Littéraires de l'Université de Besançon, 1991, pp. 391-402.
} 
Esto puede seguirse en el origen de los clubs futbolísticos andaluces a principios de la década de 1890: el Huelva Recreation Club (1889) y el equipo inglés de Sevilla (1890), embrión informal de la práctica del fútbol en esa capital donde más tarde aparecería el Sevilla F. C. (1905). Ambas plataformas respondían al origen inglés de sus practicantes - con escasísimas excepciones locales_-, a su afinidad profesional — vinculada a las minas de Riotinto en Huelva y a la «Seville Water Works Company» que construía desde 1883 la red de abastecimiento de agua en Sevilla-, así como a la procedencia social de sus asociados. La Sociedad Sevilla Balompié, nacida en 1907, no rompía el esquema apuntado, excepto en su origen autóctono. Sus socios fundadores procedían de la misma Escuela Politécnica y, mayoritariamente, acabaron todos ellos ejerciendo la carrera militar ${ }^{15}$. Si bien se hace necesario distinguir modelos de sociabilidad matizados, es evidente que se trata de clubs que se articulaban en función de la privacidad.

En tercer lugar, los primeros clubs españoles fomentaron, como sus referentes británicos de mediados de siglo, el amateurismo en tanto que valor máximo del deporte moderno inicial. Sin duda, en general no contemplaron la profesionalización en la práctica ni en la gestión institucional. Los propios practicantes eran los gestores y organizadores, lo cual era entendido como una parte implícita de la sociabilidad deportiva. Si bien esto plantea ya inicialmente un alto grado de voluntarismo y compromiso con la entidad y con la propia disciplina deportiva, también se convierte a menudo en un primer filtro social y una selección insalvable para los sectores económicamente menos favorecidos. Caso que se hace muy visible en los primeros promotores deportivos españoles, los cuales ejercen a la vez de practicantes, directivos, gestores y divulgadores publicistas, hasta el punto que es usual que los mismos individuos pueden jugar estos roles diferentes én múltiples disciplinas deportivas. Son sportmen polivalentes, más que deportistas en un sentido especializado. El caso del madrileño Narciso Masferrer [1867-1941] es paradigmático: presidente de la Unión Velocipédica Española, fue promotor de la Federación Gimnástica Española, fundó y dirigió el periódico Los Deportes (1897) en Barcelona y El Mundo Deportivo en 1906, fue directivo del F. C. Barcelona, impulsor del movimiento olímpico catalán y posteriormente del Comité Olímpico Español (1926).

Como veremos más adelante, desde la perspectiva asociativa, la profesionalización deportiva en la tercera década del siglo XX facilitó en gran medida la democratización de la práctica en algunos deportes. El amateurismo deportivo, sin embargo, se desvaneció ya en el siglo XIX en algunos ámbitos deportivos que habían nacido muy ligados a las apuestas o al espectáculo ya en Inglaterra.

No es de extrañar, por tanto, que en España el fomento de la hípica, muy característico del tiempo de ocio adinerado en la segunda mitad de la centuria,

15 SALAS, Nicolás: Sevilla. Anales del siglo XX, vol. 1 (1900-1950), Sevilla, Ed. Castillejo, 1999, pp. 170-171. 
apareciera en casi todos los centros urbanos relacionado con sociedades de «Cría Caballar» y entidades dedicadas al espectáculo. La construcción de hipódromos en Madrid, Sevilla y Barcelona, por citar algunos, fomentó un tipo de sociabilidad deportiva muy específica, evidentemente elitista, vinculada al estamento militar y aristocrático. En Sevilla, la «Sociedad de Carreras de caballos», dirigida por el Marqués de Paradas a principios del siglo XX, había construído un Hipódromo en la Dehesa de Tablada en 1874 y llegaba a cobrar 50 pesetas de entrada por un Palco de seis asientos. El hipódromo barcelonés de «Can Tunis» (1883), construído por la Compañía Francesa de Carreras de Caballos por impulso del Círculo Ecuestre y el «Fomento de la Cría Caballar», marcaba una jerarquía económica diáfana en su entrada: público de pié, tribuna, ubicación en la «pelouse» central y palcos para los socios de los clubs promotores ${ }^{16}$.

El auge hípico, por razones obviás, tuvo su edad de oro a finales del Ochocientos y pronto se estancaría frente a la creciente popularización de los deportes atléticos de los años diez del siglo XX, quedando como un reducto de sociabilidad deportiva decimonónica. Significativamente, a partir de 1900, el hipódromo de "Can Tunis» cayó en desuso para su función inicial y fue utilizado hasta su cierre por múltiples entidades deportivas. No sorprende que, también en Madrid, el Hipódromo de la Castellana fuera utilizado como escenario polideportivo desde los inicios del siglo XX, como por ejemplo para los primeros partidos de baseball en la capital ${ }^{17}$.

Otra de las características muy comunes de los primeros clubs deportivos es el importante papel de la normativización y reglamentación. En España, este aspecto es esencial a pesar del vacío legal sobre esta materia hasta bien entrado el siglo XX. Si bien es cierto que la intitucionalización de los clubs deportivos se recogía implícitamente en la Ley de Asociaciones de $1887^{18}$, lo cierto es que es difícil conocer con exactitud cuantos de los primeros clubs llegaron a registrarse y cuantos desaparecieron sin haberlo hecho.

Sin embargo, lo que parece claro es que en su gran mayoría, tuvieran o no un registro efectivo en el Gobierno Civil, internamente se estructuraban a través de una reglamentación estricta. En parte por razón de la propia procedencia profesional de sus asociados -militares, diplomáticos, empresarios, rentistas, profesionales liberales, juristas... - usualmente acostumbrados a un funcionamiento profesional disciplinado y reglamentista, en parte por la propia reglamentación del club inglés al que imitaban, y en parte por el mismo ejercicio de responsabilidad

16 Pujadas, Xavier y SAntaCana, Carlēs: Deporte, espacio y sociedad en la formación urbana de Barcelona (1870-1992), Barcelona, Fundación Barcelona Olímpica, 1999, pp. 23-26.

17 Para este último caso, ver CORRAL, José del: El comienzo de la preocupación por el ejercicio físico en Madrid. Notas para su bistoria. 1800-1875, en Orígenes del deporte madrileño, Madrid, Comunidad Autónoma de Madrid, 1988, vol. 1.

18 PASTOR, José Luis: El espacio profesional de la educación física en España: génesis y formación (1883-1961), Alcalá de Henares, Universidad de Alcalá, 1997, p. 154. 
de los dirigentes con sus consocios y con las autoridades públicas a las cuales a menudo invitaban a compartir o presidir de forma honorífica el club.

En buena medida, este hecho exigía un tipo de sociabilidad muy fundada en la jerarquía de la vida social interna, la autoridad del dirigente y la autodisciplina del asociado, aspectos que de otro lado aparecían como muy asociados a la versión más purista del deporte inglés. En los Estatutos del Sportmen's Club de Barcelona, por ejemplo, se establecía en 1903 que solamente los diez socios fundadores tenían voz y voto en la junta general; eran también los únicos que podían acceder a cargos directivos y que podían presidir las juntas de las secciones ${ }^{19}$. A pesar de todo, la organización social interna de los clubs, si bien siempre aparecía normativizada como elemento imprescindible para su estructuración organizativa, variaría progresivamente hacia una cierta democratización con el paso del tiempo y cada vez más hacia la distinción entre socios practicantes o deportistas y socios directivos. La paulatina profesionalización deportiva hizo inviable un sistema que mantuviera la polivalencia de los asociados.

Finalmente, es necesario observar cómo formó parte de la sociabilidad deportiva de los primeros años la incorporación de la promoción interna y externa de los clubs como elemento inprescindible de la vida asociativa. Sobre la comunicación entre los socios, a medida que las entidades crecieron, se hizo ineludible la publicación de boletines o revistas internas, que a su vez se utilizaban a menudo como plataformas de promoción externa. De hecho, se trataba de publicaciones que se convertirían en los embriones de la prensa deportiva española de los años iniciales (por ejemplo, el madrileño Boletín de la Unión Velocipédica Española (1898) o el barcelonés Los Deportes (1897), vinculado inicialmente a la Federación Gimnástica Española), y que mezclaban las notas de sociedad, los calendarios deportivos de los propios clubs y de la oferta regional o local, con reseñas de competiciones, noticias de actualidad deportiva en el extranjero -durante mucho tiempo funcionaron como el único puente de unión con la realidad deportiva del exterior-y artículos postulantes.

La profesionalización y la popularización progresiva de prácticas como el fútbol, el boxeo o el ciclismo durante las primeras décadas del siglo XX transformará el panorama publicístico - lo especializará, profesionalizará y racionalizará desde el punto de vista empresarial- pero, sobretodo, introducirá nuevas fórmulas de sociabilidad en la vida interna de los clubs españoles, que seguirán siendo el ámbito fundamental del desarrollo sociodeportivo.

\section{DE LAS ÉLITES A LAS MASAS}

Desde el principio, el deporte moderno estaba «condenado» a una dinámica de crecimiento y transformación. Por una parte, los clubs más elitistas necesi-

19 Ver Revista Deportiva, Barcelona, Septiembre de 1905. 
taban, a pesar de su voluntad restrictiva, organizar un entramado competitivo mínimo que garantizase la continuidad de sus actividades. En un sentido distinto, los que creían en las virtudes sociales de la práctica deportiva forzosamente habían de centrar sus esfuerzos en la popularización y democratización del deporte. Así, de una u otra forma, todos los sectores implicados favorecían el crecimiento de la actividad, lo que llevaría, muy posiblemente, también a su democratización. No obstante, el crecimiento del deporte no se produjo ni por el éxito de los que insistían en sus aspectos benéficos, ni por el impacto de unas políticas públicas estatales inexistentes. En definitiva, pues, el paso decisivo que convirtió el deporte en un fenómeno social provino de su vertiente espectacular.

Este hecho fue trascendental, porque supuso la irrupción de un modelo de deporte-espectáculo antes que se hubiera consolidado el del deporte de los practicantes. Una situación que fue perfectamente captada por los coetáneos, que se enzarzaron en un importante debate sobre este cambio de orientación, fundamental para entender los cambios que se derivaron en la organización de aquellos clubs pioneros. Buena parte de los intelectuales y defensores de la cultura física criticaron la preponderancia del espectáculo sobre la práctica deportiva, argumentando que el triunfo de éste era encubridor de la precaria situación del deporte de base, de los déficits infraestructurales y del absentismo de los poderes públicos.

Desde estos núcleos de opinión, la crítica al espectáculo se acompañaba, lógicamente, de la crítica al profesionalismo, de manera que se llegaba a comparar, en un sentido peyorativo, la nueva dimensión del deporte espectacular con las corridas de toros. La mayoría de referencias al nuevo deporte-espectáculo tenían que ver con el futbol, que se iba distanciando claramente de la dinámica de otras disciplinas deportivas. En realidad, el futbol transmutó de un modelo a otro en un tiempo récord, de manera que resultaba muy paradójico a algunos de los que vivieron ese proceso. Muy beligerante, el periodista deportivo y. económico Pedro Rico, en aquellos momentos redactor jefe del diario deportivo bilbaíno Excelsior, publicó en 1930 en Madrid el libro El «Sport» en España. Amateurs y profesionales. Educación, distracción y espectáculo ${ }^{20}$, en el que desautorizaba al fútbol precisamente porque se había convertido en un espectáculo.

No obstante, la realidad se iba imponiendo. Como es lógico, la profesionalización no se extendió ni a todos los deportes ni con la misma intensidad. Por lo tanto, su influencia en la evolución de la sociabilidad deportiva también fue distinta. En España, este fenómeno no fue importante hasta la segunda mitad de la década de 1910, y ya era notorio en la década siguiente en los clubs de futbol y ciclismo, además del caso del boxeo, aunque aquí con características particulares por el papel que tenían las apuestas y la existencia de los managers. La llegada del profesionalismo en el fútbol fue progresiva, aunque vale la

20 RICO, Pedro: El «sport» en España. Amateurs y profesionales. Educación, distracción, espectáculo, Madrid, Javier Morata, 1930.

Hispania, LXIII/2, núm. 214 (2003) 505-522 
pena citar que su reglamentación por parte de la Federación se produjo en 1926, sin ninguna intervención estatal ${ }^{21}$.

Pero, como decíamos, las bases del fenómeno eran anteriores. Los primeros pasos para disociar la figura del jugador de la del socio activo de una entidad se empezaron a producir en Barcelona los primeros años del siglo XX. Algunos jugadores exitosos consideraban que ya hacían una aportación importante a su club, y dejaban de pagar las cuotas que les correspondían como socios. Por lo tanto, de momento sólo se trataba de amateurs que no contribuían como socios. Poco a poco, se introdujeron algunos premios en especies, que no se reconocían públicamente. Así, la figura del sportmen amateur declinaba rápidamente, y sólo cabía un paso más para llegar al profesionalismo. De momento, se trataba de un profesionalismo no reconocido, que la prensa de la época calificaba como «amateurismo marrón».

Obviamente, la crisis del amateurismo tuvo grandes repercusiones en la manera de entender el deporte, y por ende, en las funciones y organización interna de los clubs. ¿Tenían todos los socios el derecho a jugar? ¿O sólo los mejores, que se iban diferenciando, utilizando su prestigio? Finalmente, ¿quién debía dirigir los clubs? En un club tan representativo de esta etapa como el F.C. Barcelona, estas discusiones se produjeron en 1911-1912 y llegaron a generar una pequeña escisión en la entidad.

La referencia a estos precedentes de la década de 1910 es necesaria para entender el impacto que causó la extensión del profesionalismo en el fútbol la década siguiente, y sus consecuencias. En la década de 1920, el proceso se había precipitado, y el modelo del sportmen como un hombre distinguido había dejado paso a la figura del joven triunfador, mito de las masas y símbolo de los tiempos modernos. Y éste era, obviamente, profesional. Es entonces cuando se inicia la dinámica de fichajes, contratos, traspasos, derechos de retención de los clubs, que inicialmente es reducida, pero que abre una nueva dinámica en que los clubs dejan de estar pensados para la práctica y pasan a ser gestionados pensando en generar espectáculo. Todo un cambio de filosofía con innumerables consecuencias prácticas y en el modelo de sociabilidad interna.

Como es lógico, estos deportistas que destacaban y conseguían éxitos en los primeros campeonatos podían reclamar un papel diferente, siempre que las disciplinas en las que competían generasen un interés suficiente por parte de una nueva categoría de individuos, los espectadores, que podían o no ser socios de un club, pero que se definían prioritariamente como espectadores, y secundariamente como socios. Este hecho explica que los deportistas dedicados al fútbol se pudiesen profesionalizar, mientras que esto no sucedía en otros deportes.

21 Un resumen de este proceso en nuestro artículo «La mercantilización del ocio», ya citado. Más ampliamente, ver MARTialay, Félix: La implantación del profesionalismo en el futbol español y el nacimiento accidentado del torneo de Liga, Madrid, Real Federación Española de Futbol, 1996.

Hispania, LXIII/2, núm. 214 (2003) 505-522 
En España, en la década de 1920, las tres especialidades con más seguidores eran el fútbol, el boxeo y el ciclismo. El boxeo empezó a trascender de los gimnasios para ocupar los campos de fútbol y las plazas de toros, donde miles de personas podían presenciar los combates más importantes. Pero, evidentemente, donde se produjo el salto más decisivo fue en el fútbol. El atractivo popular de este deporte desborda los espacios ciudadanos que utilizaba hasta entonces, y se inicia una época de construcción de grandes estadios. San Mamés, construído en 1913 en Bilbao, sería uno de sus primeros referentes, y por eso precisamente fue apodado «la Catedral», pero ya en la década de 1920 conviene resaltar los casos del Estadi Català (1921), Les Corts (1922) y Sarrià (1923) en Barcelona.

El Real Madrid erigió en 1923 su campo de Ciudad Lineal, con capacidad para 6.000 espectadores, pero sólo como una situación de transición que culminó al año siguiente al construir el estadio de Chamartín, con un aforo de 16.000 personas. La construcción de este campo fue clave para la popularización del club, que se convirtió en el hegemónico de la ciudad, gracias a una política de precios estudiada para un acceso masivo de sectores populares ${ }^{22}$. $\mathrm{Al}$ mismo tiempo, también es importante señalar que las expectativas del negocio futbolístico decidieron a una empresa a levantar el madrileño Stadium Metropolitano (1923), con capacidad para 20.000 espectadores, que se convirtió en la sede del Atlético de Madrid.

Además, la construcción de estadios significó un paso más en la intervención ciudadana de sus promotores, que normalmente eran los clubs. Ese fue el caso de los estadios semipúblicos, propiedad de los clubs, y las implicaciones económicas y urbanísticas que se derivaban de la gestión de estos espacios. La propiedad de la instalación deportiva añadía un nuevo elemento de complejidad a la gestión de los clubs, ya que existía un patrimonio a conservar. No obstante, eran muy pocos los clubs con capacidad económica suficiente para hacer frente a estos gastos. Los que no tenían capacidad pero querían seguir aquella carrera tuvieron que depender de mecenas que, indirectamente podían convertirse en propietarios del club, circunstancia absolutamente irregular. Este fue el caso del R.C.D. Español de Barcelona, que jugaba en el estadio de Sarrià, que había sido adquirido por los hermanos La Riva, miembros de la directiva, a título personal. La disociación entre el club y estos propietarios privados del terreno del estadio generó posteriormente problemas que acabaron en los juzgados.

De otro lado, es imposible entender el rumbo de esta nueva dinámica espectacular sin tener en cuenta que la erección de estadios, el surgimiento de ídolos populares, el papel de la prensa de masas y la captación de socios por

22 La dinámica del futbol madrileño, y muy especialmente la del Real Madrid de esta época, deben seguirse en los interesantes libros de BAHAMONDE, Ángel: El Real Madrid en la bistoria de España, op. cit., y de ESCANDELl BONET, Bartolomé, GonZÁlez CALlejA, Eduardo y VillacorTa BAÑOS, Francisco (Eds.): Historia del Real Madrid 1902-2002. La entidad, los socios, el madridismo, León-Madrid, Editorial Everest-Fundación Real Madrid, 2002, 2 t.

Hispania, LXIII/2, núm. 214 (2003) 505-522 
parte de los clubs eran distintas manifestaciones de un mismo fenómeno. Así, es fácil seguir esta dinámica a través del incremento de la masa social de las entidades que más decididamente dan el salto al espectáculo, de manera que las diferencias con las que no lo hacen se agrandan notablemente.

El caso paradigmático del correlato entre espectáculo e incremento de la masa social es el del F. C. Barcelona, que entre 1921 y 1924 pasa de 4.302 a 12.207 socios, coincidiendo con la fase de alza del mito de Josep Samitier y la construcción del campo de Les Corts en 192223. El caso del Real Madrid es un poco posterior, ya que los mil socios de 1922 sólo llegaron a 5.000 hasta 1933. Por el contrario, los clubs en que no se produjo este incremento de socios sufrieron una progresiva dependencia de mecenas que se convertían de hecho en propietarios de facto. Lo advertía premonitoriamente el semanario Los Deportes en 1929, cuando afirmaba que en un futuro próximo «los clubs de futbol serán sociedades anónimas, o un equipo estará a sueldo de un comerciante especializado».

Finalmente, no podemos olvidar dentro de este proceso los cambios acaecidos en la prensa deportiva, que dejó de ser portavoz de entidades o de minorías postulantes para convertirse en los principales promotores y divulgadores del espectáculo deportivo, especialmente a través de la prensa gráfica y también con la prensa humorística, dos soportes que hacían mucho más fácil la difusión en públicos amplios ${ }^{24}$.

Aunque este paso a la espectacularización sea la principal novedad de la época, y el modelo que a la postre se impuso, no debemos creer que en ese momento la mayoría de entidades deportivas hiciese esa opción. Ya hemos advertido que su concreción se plasmaba en unas pocas prácticas, pero al mismo tiempo este proceso coexistía con la multiplicación, sobre todo durante la II ${ }^{\mathrm{a}}$ República, de muchas asociaciones deportivas de origen popular, y que representaban una sociabilidad alternativa. Se trataba de pequeñas entidades de barrios populares que luchaban por la democratización de la práctica deportiva y que entendían que el acceso de las clases populares era fundamental ${ }^{25}$. En Cataluña, estas asociaciones llegaron así a generar un movimiento exclusivamente catalán, llamado «deporte popular». Y en otras zonas, se tradujo en una muy leve influencia de los postulados del deporte obrero europeo, con modelos organizativos y de sociabilidad alternativos a los del llamado deporte burgués,

23 Una de las visiones más completas de la historia social del F.C. Barcelona, en que puede seguirse su dinámica asociativa, es la obra colectiva dirigida por SOBREQUÉs Jaume (Ed.), Història del Futbol Club Barcelona, Barcelona, 1993, 6 vols.

24 Sobre la prensa deportiva, ver ALTABella, José: «Historia de la prensa deportiva madrileña», en Del CORRAL, José et al.: Orígenes del deporte madrileño. 1870-1936. Condiciones sociales de la actividad deportiva, Madrid, Comunidad de Madrid, 1988, y, para el caso de Cataluña, PUjADAS, Xavier y SANTACANA, Carles: L'esport és notícia. Història de la premsa esportiva a Catalunya (18801992), Barcelona, Col.legi de Periodistes de Catalunya, 1997.

25 Pujadas, Xavier y SANTACana, Carles: «Del barrio al estadio. Aspectos de la sociabilidad deportiva en Cataluña en la década de los años treinta», Historia y Fuente Oral, Barcelona, $n^{\circ} 7$, 1992, pp. 31-45. 
por ejemplo con una presencia notoria de organizaciones como la Federación Cultural Deportiva Obrera, próxima al P.S.O.E., en Valencia o Madrid ${ }^{26}$.

La revolución que se produjo durante la Guerra Civil en el campo republicano supuso una experiencia especial en los clubs deportivos. Es curioso constatar que en los clubs de futbol profesionales los jugadores optaron por obviar su condición y no actuaron como obreros. En cambio, la colectivización o el control obrero de las entidades pasó por la creación de comités obreros formados exclusivamente por el personal auxiliar de las entidades, pero sin la presencia de los deportistas. El único caso en el que el espectáculo deportivo fue considerado como una actividad económica con todas sus consecuencias fue el del boxeo. Aquí, los deportistas sí formaron parte de la colectivización, como única forma de eliminar el papel de sus empresarios, que no eran los clubs o los gimnasios sino los managers y los promotores de las veladas.

\section{EL NUEVO ORDEN. DEPORTE Y FRANQUISMO}

La instauración del régimen franquista supuso un cambio radical en la sociabilidad deportiva. De hecho, ya durante la Guerra Civil se empezó a esbozar en la zona franquista un hecho absolutamente nuevo: el deporte dejaría de formar parte de la sociabilidad autónoma de la sociedad para pasar a estar sometido a los designios del poder político. Esta opción llevó a crear en 1938 el Consejo Nacional de Deportes, que se transmutó en 1941 en Delegación Nacional de Deportes de Falange Española Tradicionalista y de las J.O.N.S., el partido único [D.N.D.].

De esta forma, las organizaciones deportivas perdían su carácter privado. El poder político se apropió del deporte, y el nuevo estado franquista cedió su control concreto a la Falange, en una línea teórica que predicaba el control absoluto de la sociedad por parte del partido único. Este hecho tuvo un notable impacto, no sólo porque lo ejercía una dictadura fascista, que intentó implantar en esta temática la máxima de que el partido único debía integrar el conjunto de las actividades sociales de la población. En este sentido, la opción tomada debe contemplarse en relación a las propuestas que desde Falange se hicieron respecto del control y encuadramiento de sectores como las mujeres (Sección Femenina), trabajadores (Delegación Nacional de Sindicatos), estudiantes universitarios (Sindicato Español Universitario), jóvenes (Frente de Juventudes).

Además, esta opción se aplicaba a un ámbito deportivo que no había sido objeto anteriormente de una política estatal específica, en ese caso de un régimen político democrático. Por eso, el impacto fue todavía mayor, porque descabezó directamente unas formas organizativas en que clubes y asociaciones

26 Para seguir el contraste entre la situación española y otros casos europeos, ver ARNAUD, Pierre: Une histoire du sport ouvrier en Europe, Paris, L'Harmattan, 1994. 
deportivas habían gozado de una absoluta libertad y autonomía de movimientos. Por este motivo todas las normas en que se basaba la relación entre clubs deportivos tenía su origen en sus propios usuarios, y sin interferencia estatal.

En consecuencia, el nuevo estado franquista no tuvo necesidad de desmontar una estructura estatal anterior, sino que simplemente implantó la nueva fórmula. Así se dedicó a normativizar, regular y controlar toda la actividad deportiva. El franquismo sabía que los clubs y asociaciones deportivas no eran agrupaciones sociales sin coloración ideológica. Al contrario, tenían muy claro la significación cultural, social y política de las diversas tradiciones acuñadas por las asociaciones deportivas a lo largo del primer tercio del siglo XX.

Por eso, la primera acción fue lógicamente de carácter represivo, con la desaparición de entidades consideradas como próximas a postulados republicanos, obreristas o nacionalistas. Al mismo tiempo, también procuraron la desnaturalización de las connotaciones socioculturales de muchas entidades, a través del cambio forzozo del nombre del club, o de la eliminación de algunos símbolos en sus emblemas y escudos, así como la prohibición de algunos de sus himnos. La consabida eliminación de nombres que se consideraban extranjerizantes fue quizás la parte más visible, pero no la única.

Además, la instauración de la D.N.D. significó también una impresionante uniformización donde antes había prevalecido la diversidad de situaciones. La D.N.D. uniformizó al conjunto de las disciplinas deportivas, de manera que establecía los mismos requisitos y controles a clubes de golf que a entidades futbolísticas; a saber, a entidades elitistas que a aquellas populares o a otras que fundamentaban su actividad más en el espectador que en el practicante. Al mismo tiempo, esa uniformización tenía otra traducción en la estructura territorial, que ahora se quería clónica, cuando partía de enormes diferencias entre las distintas zonas del país.

Este nuevo estado de cosas afectó decisivamente, como se puede presuponer, la vida interna de las entidades deportivas. De entrada, desaparecía la misma idea de sociedad formada por iguales, consubstancial a los ideales liberal-democráticos. Los socios, formalmente iguales, no tenían capacidad para elegir a los dirigentes asociativos, ya que éstos eran nombrados directamente por una instancia superior, que en este caso era la federación regional de su especialidad, fuese ésta el fútbol o la natación, por poner dos ejemplos. Esta situación experimentó ligeras modificaciones como la que se introdujo en 1951, que suprimía la necesidad de que dos miembros de la junta fuesen de Falange y eliminaba el sistema de ternas. No obstante, la elección hecha por la asamblea general de socios debía ser ratificada por la federación nacional respectiva, que mantenía el derecho de nombrar directamente a los miembros de la junta en caso de que rechazase dos veces la propuesta de los socios ${ }^{27}$.

27 Ver «Nuevas normas para la constitución de Juntas directivas de las sociedades deportivas», Boletín Oficial de la Delegación Nacional de Deportes, $\mathrm{n}^{\circ} 93$, Enero de 1951, p. 10. 
De esta forma, no sólo los clubs no tenían un funcionamiento democrático, sino que las federaciones no tenían nada que ver con las que habían existido hasta 1936. Antes, constituían el marco de acuerdo entre entidades libres e iguales, mientras que ahora las federaciones tenían un claro papel de control sobre los clubs, y desempeñaban una función jerárquica. En este caso, las regionales eran el eslabón de control de las entidades ante las federaciones nacionales. Y éstas, a su vez, formaban parte de una cadena de mando que culminaba en la Delegación Nacional de Deportes. La cúspide de este organigrama era ocupada por el delegado nacional, nombrado directamente por el secretario general del movimiento; es decir, por el líder de Falange. Los estatutos de los clubs recogían obligatoriamente el sometimiento de las entidades a las disposiciones y el poder jerárquico de la D.N.D., y en caso contrario no conseguían acceder a la legalidad y, por ende, participar en las competiciones.

No obstante la rigidez que demuestra este funcionamiento, los jerarcas de Falange no pretendían que la cadena de entidades deportivas se convirtiesen en correa de transmisión de los ideales del partido. En realidad, todo el entramado expuesto tenía como finalidad principal el control, y no tanto el adoctrinamiento. Esta otra misión, considerada mucho más elevada y relevante, debía ser desempeñada por una minoría. De esta manera, se consideraron conceptualmente tres ámbitos de sociabilidad deportiva. De un lado, los deportes que se desarrollaban bajo el control de los militares, ámbito sobre el cual la Falange declinaba cualquier posible influencia. De otro, los llamados deportes del Movimiento y, finalmente, los que se cursaban a través de las federaciones respectivas.

Como ya hemos visto, el deporte federativo se organizaba a través de clubs, que en primer lugar debían superar la depuración política, y luego serían sometidos a un estricto control. En cambio, los deportes del Movimiento se canalizaban a través de las organizaciones sectoriales de Falange, y debían convertirse en una actividad con clara finalidad de formar física y caracterialmente a los militantes falangistas, minoría llamada a conducir al país. Esta actividad se desarrollaba en el Frente de Juventudes, el Sindicato Español Universitario, la organización Educación y Descanso, y la Sección Femenina de Falange. Aquí, el deporte no tenía un valor competitivo, sino como elemento de formación, de tal manera que se mantuvo una clara separación, con campeonatos y encuentros propios, que ayudaron a dar cohesión al partido. Claro está que esta voluntad fue perdiendo operatividad real con el paso del tiempo, pero hubo casos en que se manifestó la clara voluntad de defender un proyecto específico, basado precisamente en los contenidos ideológicos que se le suponían a su enfoque de la actividad, como el caso de la Sección Femenina bien entrada la década de 1960.

Así pues, al referirnos a la sociabilidad deportiva en la etapa franquista, son muchas las limitaciones que debemos tener en cuenta. A pesar de desarrollarse en este marco represivo de las disidencias y contrario a la democracia interna de las entidades, lo cierto es que una vez superada la fase más aguda de la posguerra, la década de 1960 vivió un importante aumento de los practicantes afilia- 
dos a clubs deportivos, al mismo tiempo que el esquema implantado por la D.N.D. en 1941 fue cada vez más obsoleto en la práctica, excepto en el mantenimiento del control de la vida asociativa.

Sin embargo, este control se mantuvo hasta el propio fin del franquismo. Fue en efecto hasta el final imposible una vida democrática de las entidades, a pesar de sucedáneos como las elecciones por compromisarios. Al mismo tiempo, entidades que habían tenido antes de la Guerra Civil un marcado protagonismo social, como los clubs de futbol Athletic de Bilbao y F.C. Barcelona, consiguieron en el final del franquismo recuperar parte de su protagonismo y devinieron justo lo que el régimen había querido evitar: asociaciones deportivas con una importante carga sociocultural capaces de crear o reforzar imaginarios colectivos que la dictadura perseguía ${ }^{28}$.

Así las cosas, al llegar a la transición a la democracia, la mayor parte de la estructura asociativa deportiva había ido acomodándose a los requerimientos de la dictadura, y tuvo que afrontar su «reconversión» democrática sin la ayuda de una experiencia de desarrollo en democracia, sino con la losa de un autoritarismo que preñó buena parte de sus formas de funcionamiento real. Las excepciones, aunque honrosas precisamente por haber tenido que desenvolverse en un marco hostil, eran efectivamente muy pocas.

Junto al papel articulador y racionalizador de la práctica física, el estudio histórico del asociacionismo deportivo en la España contemporánea bien nos muestra pues los tipos de relación social que se establecen y su evolución en función de los protagonistas, el marco sociohistórico en el que se integran y el discurso ideológico en el que se sitúan.

Y con los clubs - asociados en particular al fútbol-, otras estructuras de sociabilidad popular, como las peñas ${ }^{29}$, deben de enfocarse para abarcar el conjunto de las formas de sociabilidad deportiva en España. Antes de 1914, el fútbol se convierte, como vimos, en una actividad que ya comienza a jerarquizar los ocios dominicales. Hoy en día, la asistencia dominical al partido - y el paso previo o/y posterior por el bar- forma parte inseparable ya de la liturgia semanal de los ocios populares, en particular pero no sólo masculinos.

28 Ver a este respecto la obra de SHAw, Duncan: Fútbol y franquismo, Madrid, Alianza, 1987.

29 Ver Planes Ball, J. A.: "Notes per a una història social de les penyes», en Educació, activitats físiques $i$ esport en una perspectiva bistòrica, op. cit., vol. 2. 